\title{
Resources for preventing sickness absence due to low back pain
}

\author{
C. Rolli Salathé1, ${ }^{1,}$ M. Melloh ${ }^{2, \star}$, A. F. Mannion ${ }^{3}$, Ö. Tamcan ${ }^{4}$, U. Müller ${ }^{4}$, N. Boos ${ }^{5}$ and A. Elfering ${ }^{1}$ \\ ${ }^{1}$ Department of Work and Organizational Psychology, Institute for Psychology, University of Bern, Muesmattstrasse 45, Bern 9, \\ Switzerland, ${ }^{2}$ Western Australian Institute for Medical Research, University of Western Australia, Hospital Avenue, Nedlands, \\ WA, 6009 Australia, ${ }^{3}$ Department of Research and Development, Spine Centre, Schulthess Clinic, Lengghalde 2, 8008 Zurich, \\ Switzerland, ${ }^{4}$ Institute for Evaluative Research in Medicine, MEM Research Center, University of Bern, Stauffacherstrasse 78, \\ 3014 Bern, Switzerland, ${ }^{5}$ Prodorso Centre for Spinal Medicine, Walchestrasse 15, 8006 Zurich, Switzerland.
}

${ }^{\star}$ Both authors contributed equally to this study.

Correspondence to: Achim Elfering, Department of Work and Organizational Psychology, Institute for Psychology, University of Bern, Muesmattstr. 45, CH-3000 Bern 9, Switzerland. Tel: +41316313639; fax: +4131 6318212; e-mail: achim.elfering@psy. unibe.ch

\begin{abstract}
Background After an episode of non-specific low back pain (LBP) some individuals fail to return to work. The factors leading to such LBP-related sickness absence are not yet fully understood.

Aims $\quad$ To identify individual resources, over and above the already established predictors, for preventing LBP-related sickness absence in a population-based sample of workers experiencing an episode of LBP.

Methods Cohort study with 1-year follow-up. Participants were from a working population who reported an episode of acute or subacute LBP at baseline. Four potential resources-life satisfaction, doing sports, job satisfaction and social support at work-were examined for their incremental value in predicting sickness absence over and above baseline sickness absence and fear-avoidance beliefs about work.

Results In all, 279 workers participated in the study. All four resources showed an inverse relationship with regard to sickness absence. A multiple regression analysis revealed that life satisfaction as a resource protected against sickness absence, when controlling for established risk factors. Job satisfaction and social support at work minimized the influence of sickness absence at baseline and at 1-year follow-up.

Conclusions In a non-clinical working sample of individuals experiencing an acute/subacute episode of LBP, life satisfaction was a unique predictor of sickness absence after 1 year. Prevention in the occupational setting should not only address common risk factors but also occupational and individual resources that keep workers satisfied with life despite having LBP.
\end{abstract}

Key words Non-specific low back pain; prognosis; resources; risk factors; work absenteeism.

\section{Introduction}

Non-specific low back pain (LBP) is very common, with up to $85 \%$ of people experiencing an episode of it at least once in their lifetime [1]. While most individuals recover spontaneously within a few days or weeks, some individuals fail to return to work (RTW) within 3 months of the onset of sick leave [1], which can have considerable economic consequences. Direct costs of LBP in Switzerland in 2005 were estimated to be $€ 2.6$ billion [2], with medical costs comprising $6.1 \%$ of the total health care expenditure. The total economic burden of LBP to Swiss society is estimated to lie between 1.6 and $2.3 \%$ of the gross national product [2]. Similar figures can be found for most Western industrialized countries [3]. Failure to RTW leads to LBP-related sickness absence, although the individual factors determining sickness absence are not yet fully understood [4]. There is increasing evidence that no single risk factor has predominant prognostic value, but that several factors may combine to form a reasonably good prognostic model [5,6]. McGill et al. [7] found that a history of LBP with work loss is associated 
with lingering deficits in biomechanical, physiological, personal, psychosocial and motor control characteristics. Individual psychological factors such as emotional distress and pain catastrophizing are also associated with sickness absence [8]. Recently, Turner et al. [9] reported that mental health, work-related fear-avoidance beliefs and catastrophizing are all predictors of chronic work disability. Work-related psychosocial factors include unfavourable recovery expectations, and beliefs that work causes LBP and that a return to previous work tasks aggravates back problems [10]. Fear-avoidance beliefs have been shown to be associated with delayed RTW and increased sickness absence in longitudinal cohort studies $[11,12]$. In the literature, there is little evidence regarding the type of occupational and individual resources that might prevent sickness absence. The performance of regular aerobic activities seems to reduce sickness absence and the recurrence of LBP $[12,13]$, whereas infrequent aerobic exercise leads to increased sickness absence [14]. Favourable job characteristics and attitudes, including social support [14] and job satisfaction [15], may reduce sickness absence. Heikkilä et al. [16] reported an inverse correlation between life satisfaction and sickness absence.

To date, few studies have examined the prognostic value of individual resources beyond established risk factors (work-related fear-avoidance beliefs [FABQwork] [10] and previous sickness absence [5,9]) in predicting sickness absence within a population-based working sample [5]. The aim of this study was to identify individual and work-related resources predicting sickness absence in individuals with LBP. Contrary to the null hypothesis, which states no association between the acknowledged risk factors and the outcome variable sickness absence 1 year after the onset of LBP, we hypothesized that sickness absence is predicted by FABQwork and sickness absence at baseline. Further, we hypothesized that sickness absence is predicted by the resources life satisfaction, job satisfaction, doing sports and social support, and that the association between baseline absenteeism and future absenteeism is lower when occupational resources are high, i.e. that high job satisfaction and high social support moderate the influence of high sickness absence at baseline on sickness absence follow-up.

\section{Methods}

A computer-generated random sample of 2860 individuals was selected from a random sample of the German-speaking Swiss population $(n=16634)$, otherwise participating in a population-based, cross-sectional census survey to establish normal values for activities of daily living, psychological factors, general health and pain perception. The research was carried out in accordance with the guidelines of the Ethics Committee of the University Hospital in Bern, Switzerland. All individuals were contacted using a standardized telephone interview to request their consent for participation. One year later, these same individuals were contacted again (Figure 1).

Individuals were included if they had experienced an acute ( $<6$ weeks) or subacute ( $<12$ weeks) [17] episode of non-specific LBP at baseline and had responded to both baseline and follow-up questionnaires. Furthermore, they had to be of working age ( $<65$ years for men, $<64$ years for women), and do paid work at least 1 day per week.

The questionnaires were mailed to the participants and included items on LBP history and work, socio-demographics, anthropometric data and recreational activities.

The data were analysed in order to examine whether the risk factors FABQwork and sickness absence at baseline predicted sickness absence 1 year after the onset of LBP. FABQwork was measured using the work-related subcategory of the Fear-Avoidance Beliefs Questionnaire (FABQ) [8]; sickness absence at baseline was assessed by asking 'How many days were you absent from work due to LBP in the last 4 weeks?' [18]. With an open response, participants were required to indicate the number of days (with a maximum of 28 days). To test whether individual resources were unique predictors over and above the risk factors FABQwork and sickness absencebaseline, life satisfaction was assessed with the question 'Overall, how satisfied are you with your life?' ( $7=$ very satisfied, $1=$ not at all satisfied) [19]. Job satisfaction and doing sports were evaluated with the questions 'Overall, how satisfied are you with your work?' ( 7 = very satisfied, $1=$ not satisfied at all) from Kälin et al. [20] and 'Do you do sports or sport-like activities (riding a bicycle to work, hiking, yoga, etc.)?' ( $1=$ yes, $0=$ no). Finally, social support at work from supervisor(s) was assessed with the question 'When you have difficulties in your work place, how much can you rely on your supervisor(s)' [21] ( $7=$ rely completely, $1=$ rely not at all $)$.

The dependent variable sickness absence was assessed 1 year after the onset of LBP using question four of the Chronic Pain Grade Questionnaire (CPQ): 'About how many days in the last 6 months have you been kept from your work because of this pain?' [22]. Participants indicated the number of days with an open response (maximum of 180 days).

The data were analysed using multiple linear regression analysis [23], which requires interval data level. The dependent variable sickness absence, as well as sickness absence at baseline, have ratio data level, while gender and doing sports are dichotomous. Pearson correlation is equivalent to the point-biserial correlation that fits correlations between a dichotomous and an interval-level variable. Individual and work resources are measured with Likert scales ascertaining equidistant intervals between response options as a prerequisite of interval data level. Previous tests on the equidistance of intervals were accordingly proved. Before the variables were entered into the model, they were tested for multicollinearity. Comparison 


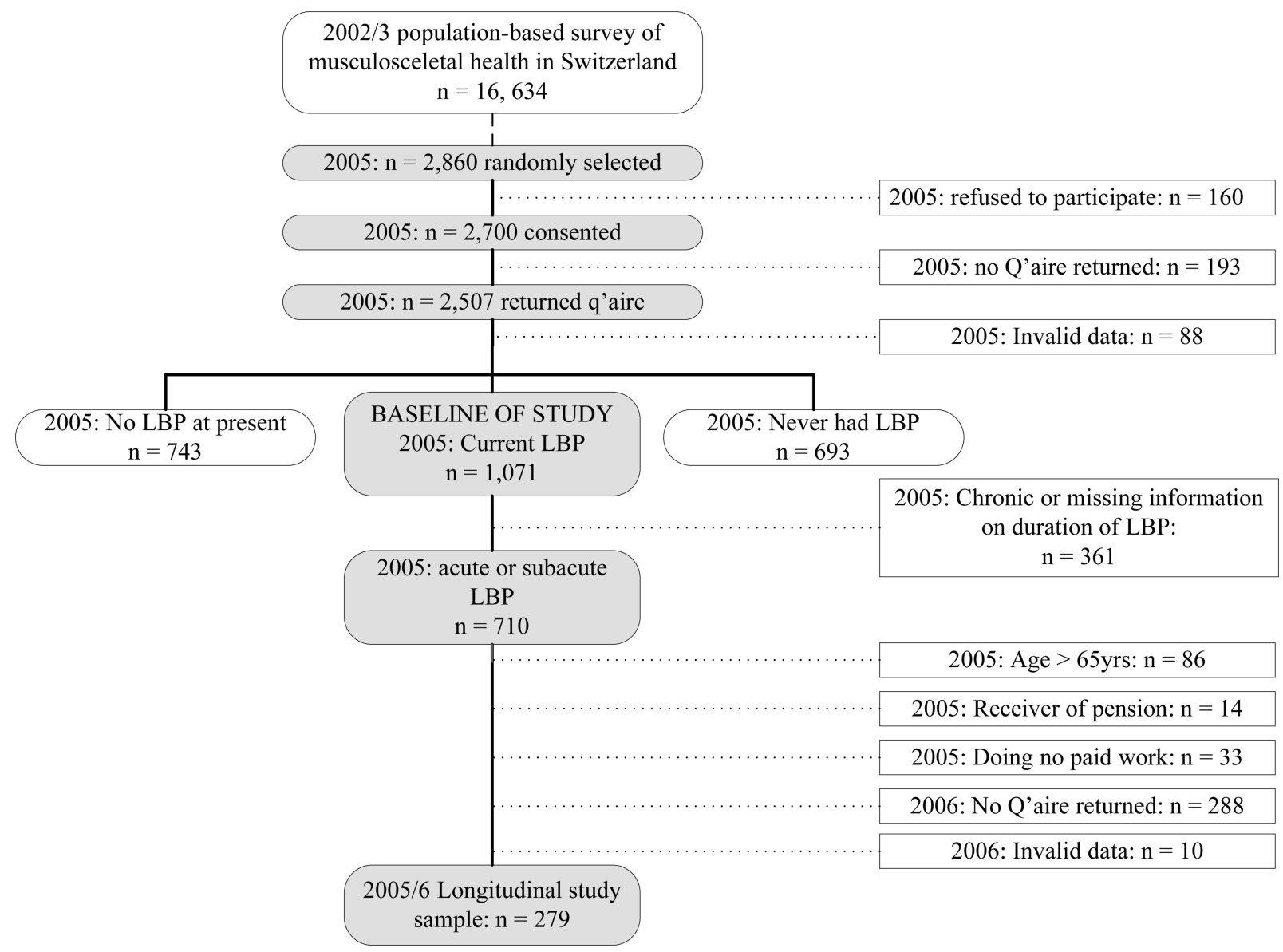

Figure 1. Flow of subjects through the study.

of the zero-order Pearson correlation coefficients between the included variables and the beta coefficients of the predictors in the regression analysis was considered useful to demonstrate how the associations between predictor variables influenced the regression model's multicollinearity pattern. No variable was allowed to have more than moderate collinearity with other predictor variables ( $<50 \%$ covariation). Furthermore, the dependent variable sickness absence was transformed into a logarithmic scale to reduce a distortion of relationships due to a non-normal distribution. To control for possible confounding factors, the variables age and gender were first entered into the stepwise regression procedure. In a second step, the risk factors FABQwork and sickness absence-baseline were entered.Then, the resources life satisfaction, doing sports, social support and job satisfaction were entered into the model to examine whether they were able to explain any further variance in sickness absence. Finally, to determine whether work resources would moderate the effects of sickness absence at baseline, the interactions between sickness absence at baseline and job satisfaction, and sickness absence at baseline and social support, were entered in a fourth step. The final regression models included eight predictor variables and one interaction. Given the sample size, a Type I error probability of 0.05 , and assuming a medium effect size in explained variance $\left(f^{2}=0.15\right)$, the power in regression analysis was $>0.95$. To calculate the predictive validity (sensitivity and specificity) for the established risk factors and resource variables, a logistic regression was conducted. For these purposes, the outcome variable sickness absence was dichotomized as 'low' and 'high' sickness absence, using the original recommendations of the authors of the CPQ, who considered individuals with a maximum of 6 days absence due to LBP as having low sickness absence, and those with more than 6 days absence as having high sickness absence [22]. All data were analysed with PASW Statistics Version 18.0 (SPSS Inc., Chicago, IL, USA).

\section{Results}

Of the 2860 individuals contacted, 279 participants met the study requirements after exclusions (see Figure 1). The average age was 43.7 ( \pm 10.3 years) with an almost equal gender distribution (female: $49 \%$ ).

Overall, 60\% (167) of participants worked full time, of whom $43 \%$ were employees, $42 \%$ were mid-level managers, $12 \%$ top-level managers and $25 \%$ were self-employed. Five per cent were in further education in addition to working and 3\% were homemakers. 
Table 1. Intercorrelations of items

\begin{tabular}{|c|c|c|c|c|c|c|c|c|}
\hline Baseline variables & $\begin{array}{l}\text { Ln sickness } \\
\text { absence at } \\
1 \text { year follow-up } \\
(n \text { days })\end{array}$ & Gender & Age & $\begin{array}{l}\text { Sickness } \\
\text { absence-baseline }\end{array}$ & $\begin{array}{l}\text { FABQ } \\
\text { work }\end{array}$ & $\begin{array}{l}\text { Life } \\
\text { satisfaction }\end{array}$ & $\begin{array}{l}\text { Social } \\
\text { support }\end{array}$ & $\begin{array}{l}\text { Job } \\
\text { satisfaction }\end{array}$ \\
\hline Gender & $-0.12^{*}$ & & & & & & & \\
\hline Age & 0.05 & $0.15^{* *}$ & & & & & & \\
\hline $\begin{array}{l}\text { Sickness } \\
\text { absence-baseline }\end{array}$ & $0.23^{* * *}$ & 0.04 & $0.17^{* *}$ & & & & & \\
\hline FABQwork & $0.24^{* * *}$ & 0.08 & 0.00 & $0.27^{* *}$ & & & & \\
\hline Life satisfaction & $-0.20^{* * *}$ & -0.01 & 0.01 & 0.03 & -0.12 & & & \\
\hline Social support & $-0.14^{*}$ & -0.03 & -0.06 & -0.05 & -0.12 & $0.30^{* * *}$ & & \\
\hline Job satisfaction & -0.06 & -0.10 & 0.10 & -0.05 & $-0.19^{* *}$ & $0.47^{* * *}$ & $0.47^{* * *}$ & \\
\hline Doing sports & -0.05 & $-0.21^{* * *}$ & -0.09 & 0.04 & -0.07 & 0.04 & 0.09 & 0.09 \\
\hline
\end{tabular}

Pearson correlations ${ }^{*} P<0.05,{ }^{* *} P<0.01,{ }^{* * *} P<0.001$.

For part-timers, $71 \%$ (79) were employees, $21 \%$ midlevel managers, $8 \%$ top-level managers and $22 \%$ selfemployed. Seven per cent were studying in addition to working and $34 \%$ were homemakers.

Of the participants, $80 \%$ (222) had not been absent from work at all; $13 \%$ reported LBP-related absence for a maximum of 6 days in the last half year, while $2 \%$ had been off work for $7-14$ days, 3\% for 15-30 days and $2 \%$ for more than 31 days. Six per cent reported sickness absence due to LBP within the last 4 weeks.

The correlation analysis revealed a significant inverse association between life satisfaction, doing sports and sickness absence 1 year after the onset of LBP. Multicollinearity analysis demonstrated a covariance below $50 \%$ (Table 1 ).

Both risk factors, FABQwork and sickness absencebaseline, predicted sickness absence 1 year after the

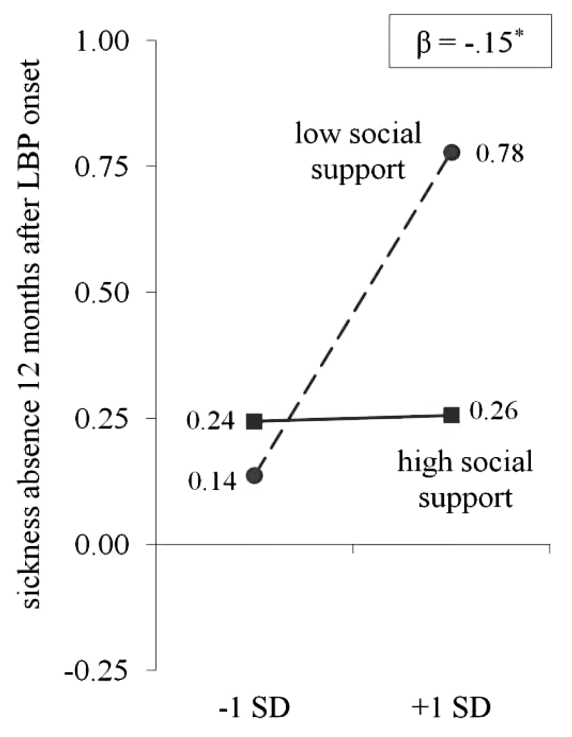

sickness absence baseline onset of LBP; first, when entered into the regression model $(P<0.01)$, as well as in the final model $(P<0.01)$, confirming that these known risk factors were indeed predictors of sickness absence 1 year after the onset of LBP. Of all the variables depicting individual resources, only life satisfaction was found to be a significant predictor of sickness absence 1 year after the onset of LBP $(P<0.01)$. In contrast, the work resources job satisfaction and social support did not, alone, explain any further variance in the dependent variable sickness absence after 1 year. However, both interactions between sickness absence at baseline and job satisfaction, and between sickness absence at baseline and social support, were similar in their ability to predict sickness absence after 1 year: both moderated sickness absence at baseline $(P<0.001 ; P<0.05)$ (Figure 2), while high job satisfaction and high social

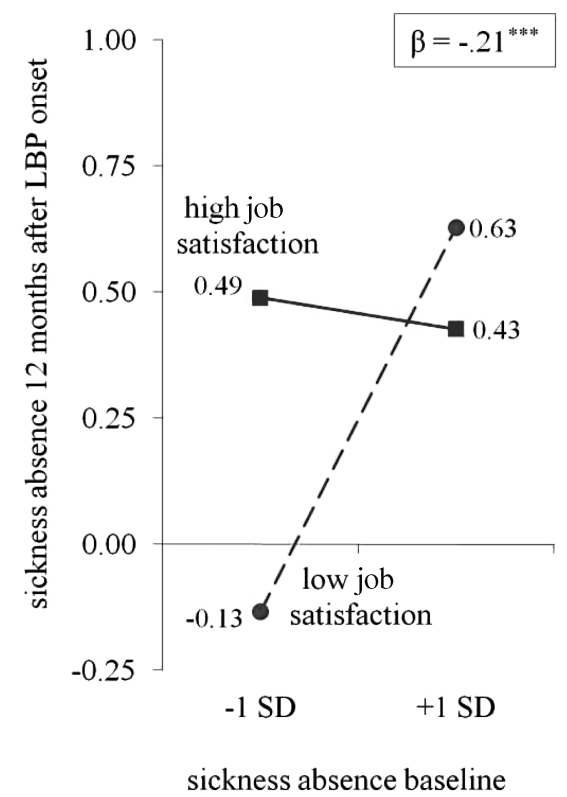

Figure 2. Significant interactions between sickness absence-baseline and work resources predicting sickness absence 12 months after onset of LBP. 
Table 2. Regression models showing predictive power of resources in reducing sickness absence

\begin{tabular}{|c|c|c|c|c|c|c|c|c|}
\hline Baseline predictor variables & $\beta(\operatorname{In})$ & $R^{2}$ change & $F$ change & Final $\beta$ & $t$ & $95 \% \mathrm{CI}$ & $\begin{array}{l}\text { Zero-order } \\
\text { correlation }\end{array}$ & VIF \\
\hline \multicolumn{9}{|c|}{ Linear regression analysis with interaction sickness absence-baseline $\times$ job satisfaction } \\
\hline \multirow{2}{*}{$\begin{array}{l}\text { (1) Gender } \\
\text { Age }\end{array}$} & $-0.13^{*}$ & & & -0.13 & $-2.1^{*}$ & $-0.5-0.0$ & -0.12 & 1.1 \\
\hline & 0.07 & 0.02 & 2.3 & 0.01 & 0.04 & $-0.0-0.0$ & 0.05 & 1.1 \\
\hline (2) Sickness absence-baseline & $0.17^{* *}$ & & & 0.18 & $2.9^{* *}$ & $0.0-0.1$ & 0.23 & 1.1 \\
\hline FABQwork & $0.21^{* *}$ & 0.09 & 12.4 & 0.16 & $2.5^{*}$ & $0.0-0.1$ & 0.25 & 1.2 \\
\hline (3) Life satisfaction & -0.21 & & & -0.19 & $-2.8^{* *}$ & $-0.3-0.1$ & -0.19 & 1.3 \\
\hline Social support & -0.10 & & & -0.09 & -1.4 & $-1.1-0.0$ & -0.14 & 1.3 \\
\hline Job satisfaction & 0.12 & & & 0.12 & 1.6 & $-0.0-0.2$ & -0.06 & 1.6 \\
\hline Doing sports & -0.09 & 0.05 & 3.7 & -0.09 & -1.5 & $-0.6-0.1$ & -0.06 & 1.1 \\
\hline $\begin{array}{l}\text { (4) Sickness absence- } \\
\text { baseline } \times \text { job satisfaction }\end{array}$ & $-0.21^{* * *}$ & 0.04 & 12.2 & -0.21 & $-3.5^{* * *}$ & $-0.1-0.0$ & -0.29 & 1.1 \\
\hline Final regression model & \multicolumn{2}{|l|}{$\begin{array}{l}R=0.45 \\
F=6.67\end{array}$} & & \multicolumn{2}{|l|}{$\begin{array}{l}R^{2}=0.21 \\
\mathrm{df}=241\end{array}$} & \multicolumn{2}{|c|}{$\begin{array}{l}\text { Adj. } R^{2}=0.18 \\
\text { Sign. } F<0.001\end{array}$} & \\
\hline \multicolumn{9}{|c|}{ Linear regression analysis with interaction sickness absence-baseline $\times$ social support } \\
\hline (1) Gender & $-0.13^{*}$ & & & -0.13 & $-2.1^{*}$ & $-0.5-0.01 .5$ & -0.12 & 1.1 \\
\hline Age & 0.07 & 0.02 & 2.3 & 0.01 & 0.1 & $-0.0-0.0$ & 0.05 & 1.1 \\
\hline (2) Sickness absence-baseline & $0.17^{* *}$ & & & 0.17 & $2.7^{* *}$ & $0.0-0.1$ & 0.23 & 1.2 \\
\hline FABQwork & $0.21^{* *}$ & 0.09 & 12.4 & 0.17 & $2.6^{* *}$ & $0.0-0.1$ & 0.25 & 1.2 \\
\hline (3) Life satisfaction & $-0.21^{* *}$ & & & -0.19 & $-2.8^{* *}$ & $-0.3-0.1$ & -0.19 & 1.3 \\
\hline Social support & -0.10 & & & -0.11 & -1.6 & $-0.1-0.0$ & -0.14 & 1.3 \\
\hline Job satisfaction & 0.12 & & & 0.13 & 1.7 & $-0.0-0.2$ & -0.06 & 1.6 \\
\hline Doing sports & -0.09 & 0.05 & 3.7 & -0.09 & -1.4 & $-0.6-0.1$ & -0.06 & 1.1 \\
\hline $\begin{array}{l}\text { (4) Sickness absence- } \\
\text { baseline } \times \text { social support }\end{array}$ & $-0.15^{*}$ & 0.02 & 5.8 & -0.15 & $-2.4^{*}$ & $-0.0-0.0$ & -0.23 & 1.1 \\
\hline Final regression model & \multicolumn{3}{|l|}{$\begin{array}{l}R=0.43 \\
F=5.82\end{array}$} & \multicolumn{2}{|l|}{$\begin{array}{l}R^{2}=0.18 \\
\mathrm{df}=241\end{array}$} & \multicolumn{2}{|c|}{$\begin{array}{l}\text { Adj. } R^{2}=0.15 \\
\text { Sign. } F<0.001\end{array}$} & \\
\hline
\end{tabular}

$\beta$ (In) stands for standardized regression coefficient when variable was entered, final $\beta$ for $\beta$ after all variables have been entered.

$R^{2}$ change and $F$ change show the amount of additional change each variable added to the final explained variance.

$t$ stands for $t$ value indicating the significance of the variable, CI 95\% for 95\% confidence interval for B (unstandardized $\beta$ value) of variable, and zero-order

correlation shows the correlation between the predictor/independent variable (IV) and outcome variable (OV). VIF (variance inflation factor) estimates the increase of the regression coefficient because of collinearity.

Adj. $R^{2}$ stands for the adjusted coefficient of determination and represents the explained variance by the model.

${ }^{*} P<0.05,{ }^{* *} P<0.01,{ }^{* * *} P<0.001$.

support also moderated the impact of high baseline sickness absence on sickness absence 1 year after the onset of LBP (Table 2).

The results of the logistic regression models differed only marginally from those described above, with the model for the interaction between sickness absence at baseline and job satisfaction revealing slightly better results (Nagelkerke's $R^{2}=0.28$ ) than the model testing the interaction between sickness absence at baseline and social support (Nagelkerke's $R^{2}=0.25$ ). The sensitivities of the two models were similar and indicated that $93 \%$ of all persons with sickness absence could be predicted; the overall predictive value of each model was also similar, at $93 \%$. However, the model that included the interaction between sickness absence at baseline and social support had better specificity, allowing $100 \%$ of all people recovering spontaneously to be predicted compared with just $75 \%$ using the interaction between sickness absence at baseline and job satisfaction.

\section{Discussion}

All individual resources examined showed negative zero-order correlations with sickness absence after 1 year, highlighting the importance of these resources in protecting against sickness absence. Further, life satisfaction proved to be a uniquely significant predictor over and above the two known risk factors, sickness absence-baseline and FABQwork. Finally, the two work resources job satisfaction and social support at work moderated the influence of baseline sickness absence on sickness absence 1 year later.

Prior sickness absence showed a moderate correlation with sickness absence after 1 year, which is in agreement with previous findings on LBP-related sickness absence $[5,9]$. In addition, and consistent with the literature [10], work-related fear-avoidance beliefs at baseline predicted sickness absence after 1 year. Both variables also showed a unique predictive value when controlling for 
age and sex, which provides further evidence that they are important prognostic factors for sickness absence.

Life satisfaction proved to be a predictor of sickness absence over and above the risk factors sickness absencebaseline and FABQwork. Few studies have investigated the combined effects of health behaviour, health perceptions and work characteristics [24]. The relationship between life satisfaction and sickness absence has been described in just one laboratory study [25], in which job and life satisfaction were assessed by role play involving positive, neutral or negative satisfaction. Shoenfelt and Battista [25] reported a positive life satisfaction that resulted in lower sickness absence. Findings in a similar direction were referred by Hanebuth et al. [24], who observed a consistent association between physical healthrelated quality of life and various absenteeism measures.

Contrary to expectations, doing sports did not prove to be a predictor of sickness absence over and above sickness absence at baseline and FABQwork. Although previous findings show the association between doing sports and reduced sickness absence $[12,13,26]$, this study does not confirm a relationship between participation in sports and sickness absence. However, a recent review based on reviews analysing the level of concordance between risk factors for sickness absence due to LBP and interventions preventing LBP disability found a moderate concordance for only one out of six risk factors and the intervention exercise, indicating that exercise might only be beneficial for 'immobilized' patients with prominent fear-avoidance beliefs [27]. Further research is needed to examine these factors and their potential influence on sickness absence.

Neither job satisfaction nor social support were significant predictors in the multiple regression analysis. Yet both work resources were found to moderate the association between baseline sickness absence and sickness absence 1 year later. This finding is in accordance with the literature, which highlights the importance of work conditions, especially supervisor support, for health issues and well-being. In relation to social support, a recent study suggested that support from both supervisors and colleagues showed significant prognostic value for long-term perceived recovery and improvement in function in people with LBP [28]. However, the study did not evaluate sickness absence as an outcome variable per se [28], and conflicting results can also be found in the literature. In assessing absence due to LBP, Hoogendorn et al. [29] found a non-significant relationship between low social support and sickness absence, despite a significant relationship between low job satisfaction and sickness absence due to LBP.

When targeting sickness absence with preventive or interventional procedures, the significant moderation of sickness absence at baseline by job satisfaction and social support implies that these work resources 'protect' against the risk of sickness absence. This is important, especially in relation to the costs due to LBP, disability and impairment $[2,4]$. By creating extended work resources, employers potentially have a powerful preventative instrument for sickness absence. Future research should test more specifically, e.g. whether social support is an antecedent of both life satisfaction and sickness absence.

To date, no studies have evaluated established risk factors for sickness absence in combination with individual and work-related resources. There is therefore a lack of evidence regarding the potential attenuation of future LBP-related sickness absence by such resources. Our findings that (i) life satisfaction is an independent resource variable and (ii) interactions between both work resources and baseline sickness absence uniquely explained variance in sickness absence demonstrate the usefulness of this multivariable approach.

The main strength of this study is its focus on resources that reduce the likelihood of LBP-related sickness absence. Since LBP-related sickness absence has notable economic consequences $[2,4]$, the prevention of LBP-related sickness absence is of importance. The study proposes that prevention may succeed best by reducing risk factors and enhancing individual resources. The European guidelines for the prevention of LBP indicate that there is limited scope for preventing its incidence, but recommend education and physical activity/ exercise as the most promising approaches for secondary prevention and treatment [12]. The primary causative mechanisms of occupational non-specific LBP still remain largely unknown and the modification of purported risk factors does not necessarily result in prevention [12]. In this respect, the promotion of personal resources to enhance one's resilience to LBP may contribute towards its prevention, or at least the prevention of associated sickness absence.

Limitations include the fact that some individuals had to be excluded from the study. However, drop-out analysis showed that baseline data did not differ between the participants that were included in the study and those that were excluded. The remaining 279 participants, out of the 773 persons with an acute/subacute episode of LBP, is a rather small sample for a population-based study. To examine the statistical power of the study, we conducted a retrospective power analysis [30] for a fixed linear regression model with given alpha (0.05), power $(80 \%)$, effect size $\left(f^{2}=0.15\right)$ and nine predictors, and ascertained that a minimal number of 89 participants would have been required for our analysis. Hence, we considered the statistical power to be adequate. The possible lack of representativeness of the sample is another limitation: since participants had to have a good command of the German language, immigrants who were included in the sample differed systematically from the average immigrant in Switzerland, as they possessed better German language skills. 
In striving to investigate an individual resourceoriented approach towards sickness absence, the present longitudinal study identified a predictor model comprising baseline sickness absence and FABQwork as established risk factors, and life satisfaction as an additional individual resource explaining further variance in sickness absence 1 year after the onset of LBP. The two non-significant resources job satisfaction and social support moderated the effect of sickness absence at baseline on sickness absence after 1 year, adding further support for the usefulness of the resources approach. Being satisfied with one's life despite having LBP, as well as social support at work and job satisfaction, appear to be beneficial with regard to work loss in the long run.

\section{Key points}

- The reasons for differences in work-related absenteeism in individuals suffering from non-specific low back pain are not yet fully understood.

- The present longitudinal study identified life satisfaction as an individual resource explaining a variance in work absenteeism beyond that which was explained by previous absenteeism, and workrelated fear-avoidance beliefs; it further identified job satisfaction and social support at work as moderators of the effect of baseline sickness absence on sickness absence 1 year later.

- Occupational and individual resources should be honed to promote occupational health.

\section{Funding}

This work was supported by a grant from the Swiss National Science Foundation, National Research Programme NRP53, Project 405340-104826/1 and Project 405340-104826/2. We also wish to thank the MHV-Programme from the Swiss National Science Foundation for their financial support in the form of a personal grant [PMCDP1_134112/1] for the first author.

\section{Conflicts of interest}

None declared.

\section{References}

1. Henschke N, Maher CG, Refshauge KM et al. Prognosis in patients with recent onset low back pain in Australian primary care: inception cohort study. $B r \operatorname{Med} \mathcal{F} 2008 ; 337$ : a171.

2. Wieser S, Horisberger B, Schmidhauser S et al. Cost of low back pain in Switzerland in 2005. Eur F Health Econ 2011;12:455-467.
3. Dagenais S, Caro J, Haldeman S. A systematic review of low back pain cost of illness studies in the United States and internationally. Spine $\mathcal{F}$ 2008;8:8-20.

4. Cooper C, Dewe P. Well-being-absenteeism, presenteeism, costs and challenges. Occup Med (Lond) 2008;58: 522-524.

5. Elfering A. Work-related outcome assessment instruments. Eur Spine f 2006;15:S32-S43.

6. Steenstra IA, Verbeek JH, Heymans MW, Bongers PM. Prognostic factors for duration of sick leave in patients sick listed with acute low back pain: a systematic review of the literature. Occup Environ Med 2005;62:851-860.

7. McGill S, Grenier S, Bluhm M, Preuss R, Brown S, Russell C. Previous history of LBP with work loss is related to lingering deficits in biomechanical, physiological, personal, psychosocial and motor control characteristics. Ergonomics 2003;46:731-746.

8. Staerkle R, Mannion AF, Elfering A et al. Longitudinal validation of the Fear-Avoidance Beliefs Questionnaire (FABQ) in a Swiss-German sample of low back pain patients. Eur Spine f 2004;13:332-340.

9. Turner JA, Franklin G, Fulton-Kehoe D et al. ISSLS prize winner: early predictors of chronic work disability. A prospective, population-based study of workers with back injuries. Spine 2008;33:2809-2818.

10. Iles RA, Davidson M, Taylor NF, O'Halloran P. Systematic review of the ability of recovery expectations to predict outcomes in non-chronic non-specific low back pain. F Occup Rehabil 2009;19:25-40.

11. Dionne CE, Bourbonnais R, Fremont $\mathrm{P}$ et al. Determinants of 'return to work in good health' among workers with back pain who consult in primary care settings: a 2-year prospective study. Eur Spine f 2007;16:641-655.

12. Burton AK, Balague F, Cardon G et al. Chapter 2 European guidelines for prevention in low back pain. Eur Spine $\mathcal{F}$ 2006;15:136-168.

13. Kuoppala J, Lamminpaa A, Husman P. Work health promotion, job well-being, and sickness absences-a systematic review and meta-analysis. $\mathcal{F}$ Occup Environ Med 2008;50:1216-1227.

14. Feuerstein M, Berkowitz SM, Huang GD. Predictors of occupational low back disability: implications for secondary prevention. f Occup Environ Med 1999;41: 1024-1031.

15. Harrison DA, Newman DA, Roth PL. How important are job attitudes? Meta-analytic comparisons of integrative behavioral outcomes and time sequences. Acad Manage $\mathcal{f}$ 2006;49:305-325.

16. Heikkila H, Heikkila E, Eisemann M. Predictive factors for the outcome of a multidisciplinary pain rehabilitation programme on sick-leave and life satisfaction in patients with whiplash trauma and other myofascial pain: a follow-up study. Clin Rehabil 1998;12:487-496.

17. van Tulder M, Becker A, Bekkering $\mathrm{T}$ et al. Chapter 3European guidelines for the management of acute nonspecific low back pain in primary care. Eur Spine f 2006;15: S169-S191.

18. Muller U, Tanzler K, Burger A et al. A pain assessment scale for population-based studies: development and validation of the pain module of the Standard Evaluation Questionnaire. Pain 2008;136:62-74. 
19. Diener E, Emmons RA, Larsen RJ, Griffin S. The Satisfaction With Life Scale. F Pers Assess 1985;49:71-75.

20. Kälin W, Semmer NK, Elfering A et al. Work characteristics and well-being of Swiss apprentices entering the labor market. Swiss f Psychol 2000;59:272-290.

21. Caplan RD, Cobb S, French RP, Jr, van Harrison R, Pinneau SR, Jr. Fob Demands and Worker Health: Main Effects and Occupational Differences. DHEW NIOSH Publication No. 75-160. Washington, DC: US Government Printing Office, 1975.

22. Von Korff M, Ormel J, Keefe FJ, Dworkin SF. Grading the severity of chronic pain. Pain 1992;50:133-149.

23. Schade V, Semmer N, Main CJ, Hora J, Boos N. The impact of clinical, morphological, psychosocial and workrelated factors on the outcome of lumbar discectomy. Pain 1999;80:239-249.

24. Hanebuth D, Meinel M, Fischer JE. Health-related quality of life, psychosocial work conditions, and absenteeism in an industrial sample of blue- and white-collar employees: a comparison of potential predictors. $\mathcal{F}$ Occup Environ Med 2006;48:28-37.

25. Shoenfelt EL, Battista L. A laboratory study of satisfaction effects on mood state, withdrawal intentions, and organizational citizenship behavior. Psychol Rep 2004;95: 803-820.

26. van den Heuvel SG, Boshuizen HC, Hildebrandt VH, Blatter BM, Ariens GA, Bongers PM. Effect of sporting activity on absenteeism in a working population. Br F Sports Med 2005;39:e15.

27. Shaw WS, Linton SJ, Pransky G. Reducing sickness absence from work due to low back pain: how well do intervention strategies match modifiable risk factors? f Occup Rehabil 2006;16:591-605.

28. Helmhout PH, Staal JB, Heymans MW, Harts CC, Hendriks EJ, de Bie RA. Prognostic factors for perceived recovery or functional improvement in non-specific low back pain: secondary analyses of three randomized clinical trials. Eur Spine f 2010;19:650-659.

29. Hoogendoorn WE, Bongers PM, de Vet HC, Ariens GA, van Mechelen W, Bouter LM. High physical work load and low job satisfaction increase the risk of sickness absence due to low back pain: results of a prospective cohort study. Occup Environ Med 2002;59:323-328.

30. Faul F, Erdfelder E, Buchner A, Lang AG. Statistical power analyses using $G^{\star}$ Power 3.1: tests for correlation and regression analyses. Behav Res Methods 2009;41:1149-1160.

\section{Top 10 most cited papers from 2011}

1. Shift work and chronic disease: the epidemiological evidence

X.-S. Wang et al.

Occupational Medicine 2011;61(2):78-89.

2. The subjective utility of early psychosocial interventions following combat deployment

$\mathrm{N}$. Jones et al.

Occupational Medicine 2011;61(2):102-107.

3. Differentiating occupational asthmatics from non-occupational asthmatics and irritant-exposed workers

W. Anees et al.

Occupational Medicine 2011;61(3):190-196.

4. Systematic review: occupational physical activity and low back pain

B. K. Kwon et al.

Occupational Medicine 2011;61(8):541-549.

5. Workplace management of upper limb disorders: a systematic review

F. D. Dick et al.

Occupational Medicine 2011;61(1):19-25.

6. Toxoplasma gondii infection in workers occupationally exposed to raw meat

C. Alvarado-Esquivel et al.

Occupational Medicine 2011;61(4):265-269.

7. Musculoskeletal injuries among overweight army trainees: incidence and health care utilization

D. N. Cowan et al.

Occupational Medicine 2011;61(4):247-252.

8. Respiratory symptoms in insect breeders

J. Harris-Roberts et al.

Occupational Medicine 2011;61(5):370-373.

9. Smoking status and immunoglobulin E seropositivity to workplace allergens

A. Adisesh et al.

Occupational Medicine 2011;61(1):62-64.

10. Occupational asthma caused by heated triglycidyl isocyanurate

W. Anees et al.

Occupational Medicine 2011;61(1):65-67. 